\title{
CORRIGENDA
}

\section{CSPa promotes SNARE-complex assembly by chaperoning SNAP-25 during synaptic activity}

\author{
Manu Sharma, Jacqueline Burré and Thomas C. Südhof
}

Nat. Cell Biol. 13, 30-39 (2011); published online 12 December 2010; corrected after print 21 December 2010;

In the version of this article initially published online and in print, grant information was missing from the acknowledgements. The acknowledgements have been updated as follows:

"We thank S. Chandra for discussions, and J. Mitchell, A. Roth and I. Kornblum for technical support. This work was supported by the National Institute on Aging (NIH grant RC2AG036614 to T.C.S.), and fellowships from the Human Frontiers Program (LT00527/2006-L to M.S.) and the 'Deutsche Akademie der Naturforscher Leopoldina' (BMBF-LPD 9901/8-161 to J.B.)."

\section{Loss of the RhoGAP SRGP-1 promotes the clearance of dead and injured cells in Caenorhabditis elegans}

Lukas J. Neukomm, Andreas P. Frei, Juan Cabello, Jason M. Kinchen, Ronen Zaidel-Bar, Zhong Ma, Lisa B. Haney, Jeff Hardin, Kodi S. Ravichandran, Sergio Moreno and Michael O. Hengartner

Nat. Cell Biol. 13, 79-86 (2011); published online 19 December 2010; corrected after print 07 January 2011;

In the version of this letter initially published online and in print, supplementary information figures S3, S4 and S5 were presented in the incorrect order. This error has been corrected in the HTML version of the letter. 